\title{
DESCARTES: DE SUA PASSAGEM PELO COLÉGIO JESUÍTA ROYAL HENRY-LE-GRAND À CRIAÇÃO DA GEOMETRIA ANALÍTICA
}

\author{
Tadeu Fernandes de Carvalho \\ Pontifícia Universidade Católica de Campinas-PUC-Campinas - Brasil \\ Priscila de Moraes \\ Pontifícia Universidade Católica de Campinas -PUC-Campinas - Brasil \\ Denise Helena Lombardo Ferreira \\ Pontifícia Universidade Católica de Campinas -PUC-Campinas - Brasil
}

(aceito para publicação em maio de 2016)

\begin{abstract}
Resumo
O presente trabalho trata de aspectos da vida e de obras de Descartes, incluindo sua passagem pela escola jesuítica Royal Henry-Le-Grand, criada pelo Rei Henrique IV em 1604 em La Flèche, na França. Destacam-se, também, a importante presença de educadores jesuítas em sua formação e algumas de suas motivações filosóficas, físicas e matemáticas para a criação da Geometria Analítica. Incluem-se reflexões de cientistas e educadores como Roger Penrose, Paulo Freire e Ubiratan D’Ambrósio, em torno dos rumos atualmente esperados para o processo de ensino e de aprendizagem da matemática no Brasil e no mundo.
\end{abstract}

Palavras-chave: Descartes, Geometria Analítica, Educação Jesuítica.

\section{[DESCARTES: FROM ITS LIFE AT COLLÈGE ROYAL HENRY-LE-GRAND TO THE CREATION OF ANALYTIC GEOMETRY]}

\begin{abstract}
Distinguished lectures detached in the present work, includes Descartes' works and passage at the jesuit school Royal Henry-Le-Grand, created by the french king Henry IV in 1604 in La Flèche. It includes also the important presence of jesuitic teachers and some of its philosophical, physical and mathematical motivations for the creation of Analytical
\end{abstract}


Geometry. Reflections of scientists and educators just like Roger Penrose, Paulo Freire and Ubiratan D' Ambrósio are included just around the process of teaching and learning mathematics in Brazil and the world.

Keywords: Descartes, Analytical Geometry, Jesuitic Education.

\section{Introdução}

Trata, o presente artigo, de uma abordagem histórica e interpretativa da formação cultural e dos objetivos pessoais e científicos de René Descartes (1596 - 1650), relacionados à criação da Geometria Analítica, associada à experiência vivida no colégio jesuíta Royal Henry-Le-Grand. Este colégio embora tenha sido criado em 1604 em La Flèche, na França, reflete as intenções ou objetivos estabelecidos pelo padre jesuíta Inácio de Loyola, que escreveu as constituições adotadas em 1554 e cuja organização enfatizava a abnegação e a obediência ao Papa e aos superiores hierárquicos. Poucos cientistas apresentam a vida e a obra tão indissociáveis, intensas e profundas quanto Descartes, nascido na pequena cidade francesa de La Haye-en-Touraine. Localizada a 300 quilômetros de Paris e próxima de Indre, Poitou e Touraine. Sua cidade natal passou a ser chamada La Haye-Descartes entre 1802 a 1969 e simplesmente Descartes, desde então. Seu pai, Joachim Descartes, era advogado, juiz e conselheiro do Parlamento de Rennes, na Bretanha. A mãe, Jeanne Brochard, faleceu quando o mesmo tinha apenas um ano, razão pela qual foi criado pela avó materna, Jeanne Sain (BAILLET, 2012).

Descartes, de família abastada e bem educada que reunia médicos e advogados, foi matriculado em 1607 no Colégio de La Flèche. Ali teve os primeiros contatos com a lógica e a filosofia de Aristóteles nas aulas do Padre Estevão de Noel, e com a Matemática, em particular com a Geometria de Euclides, por meio de obras do Padre Christophorus Clavius ou, mais adequadamente, Cristóvão Clávio (Bamberg, 1538 - Roma, 1612). A excelência da educação em La Flèche reflete, de fato, a formação científica e cultural dos padres jesuítas, dos quais Clávio, foi um dos mais brilhantes. Herdou, como outros grandes educadores portugueses de seu tempo, o brilho e a erudição de Pedro da Fonseca, padre e grande filósofo nascido em Proença-a-Nova em 1528 e falecido em Lisboa, em 1599. Graças a tais educadores, La Flèche tornou-se uma grande escola e um porto seguro para os anos incertos de Descartes.

\section{Os estudos de Descartes em La Flèche}

Elementos comuns aos sistemas educacionais do colégio de La Flèche e demais colégios de Portugal foram estabelecidos pelos educadores jesuítas, que além de aspectos dogmáticos, incluíam, como no caso da Física e da Matemática, aspectos teóricos e, também, aplicações concretas.

Em Prado e Vidal (2002), o traço comum da elitização da escola se estendia ao Ensino Superior: 
"A pedagogia escolar jesuítica, de um modo geral, possuía algumas características básicas. Além de envolver estudos e métodos de ensino assentados fundamentalmente na repetição e imitação dos textos clássicos, latinos e gregos; de ser prisioneira da orientação religiosa, contrapondo-se, em parte, ao espírito científico nascente, caracterizavase por voltar-se para a elite, constituindo-se como um elemento de distinção dessa mesma elite no interior da sociedade, um ornamento para as camadas superiores da sociedade.

Nos colégios jesuíticos e na Universidade de Coimbra, o autor fundamental era Aristóteles. Esse e são Tomás de Aquino constituíam objeto de defesa cautelosa nos colégios, tendo sido recomendado aos mestres, pelo Ratio Studiorum, que se evitasse qualquer suspeita contra as doutrinas dos mesmos". (PRADO; VIDAL, 2002, p. 174-175.)

Inúmeros clérigos ao final da Idade Média e os primeiros séculos da modernidade se dedicavam, assim, aos estudos da Matemática e da Física, ao contrário do que poderiam sugerir as restrições da Igreja Católica acerca de publicações relacionando os sistemas heliocêntrico e geocêntrico. Foi o caso do Padre Cristóvão Clávio. A Figura 1 mostra o retrato de Clávio entre as obras intituladas Álgebra e Opera Mathematica.

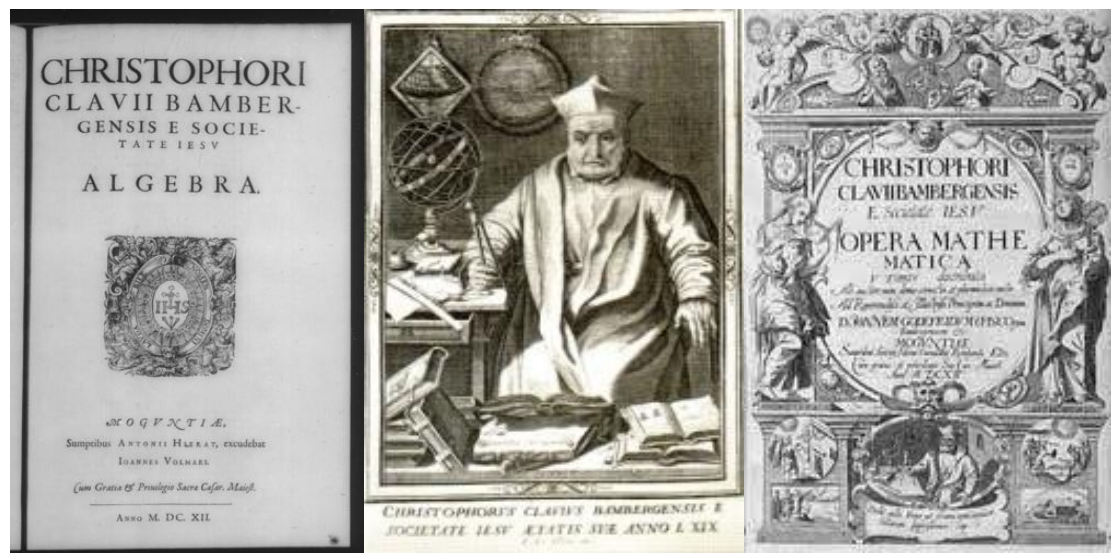

Figura 1. Clávio e duas de suas obras.

Fonte: Boston College University Libraries.

Segundo Fonseca (2013), poucos livros de Matemática e de Ciências foram publicados no século que seguiu a publicação da Bíblia de Gutenberg, em 1455. Os jesuítas, porém, reconheceram a importância da palavra impressa e produziram, ao longo dos séculos seguintes, inúmeros textos clássicos, tanto de caráter científico quanto filosófico, religioso e literário. O clérigo Ruđer Josip Bošković, ou Ruggiero Giuseppe Boscovich, por 
exemplo, nascido em Dubrovnik em 1711 e falecido em Milão em 1787, escreveu entre 151 livros e tratados. Já o clérigo Matteo Ricci (Li Madou), que viveu entre a cidade de Macerata (1552 na Itália) e Pequim (1610 na China), publicou obras missionárias, científicas, cartográficas e renascentistas, entre outras, sob a orientação de Clávio. A obra Della entrata della Compagnia di Gesù e Christianità nella Cina (Na entrada da Companhia de Jesus e do Cristianismo na China), publicada em 1609, exemplifica como o produtivo período entre os portugueses e chineses se perdeu com a extinção da Companhia de Jesus em 1773.

Clávio publicou em 1608, em Roma, a obra Álgebra, tendo sido a primeira grande referência de Descartes para a reformulação da Geometria de Euclides com base em suas propriedades e ordenações algébricas. Outra de suas importantes obras foi Euclidis Elementorum (Elementos de Euclides), na qual traduziu, criticou e comentou os Elementos e outras grandes publicações de Euclides.

Segundo Fonseca (2013), Clávio influenciado por autores próximos ou recémchegados à Idade Moderna, como Leonardo Fibonacci (1170 - 1250), estudioso de tópicos de Aritmética e de Geometria, o frade franciscano Luca Pacioli (1445 - 1514), autor da clássica obra Summa di Arithmetica, Geometria, Proportioni e Proportionalità (1494) (Sumário de Aritmética, Geometria, Proporções e Proporcionalidades), além de Girolamo Cardano (1501 - 1576), Nicolo Tartaglia (1500 - 1557) e Lodovico Ferrari (1522 - 1565), exerceu, sem dúvida, grande influência a partir do século XVII. A teoria de proporções, em particular, foi uma das chaves de leitura da realidade matemática de seu tempo, relevante, por exemplo, aos trabalhos do Padre Girolamo Saccheri, (1667 - 1733), introdutor dos fundamentos da Geometria Hiperbólica.

\section{O documento Ratio Atque Institutio Studiorum Societatis Iesu}

O Colégio de La Flèche, denominado Ratio Atque Institutio Studiorum Societatis Iesu, que seguia uma organização educacional inovadora para o seu tempo e implantada pelos jesuítas, ajudou a transformar o ensino na Europa e nas colônias portuguesas e espanholas. Sem se constituir, propriamente, em um Projeto Pedagógico para suas instituições, ações foram moldadas que se mostraram eficientes e que ainda são referências para as escolas atuais. A Figura 2 mostra um quadro de Henri IV, fundador político do Colégio de La Flèche, com sua clássica gravura de 1695. 

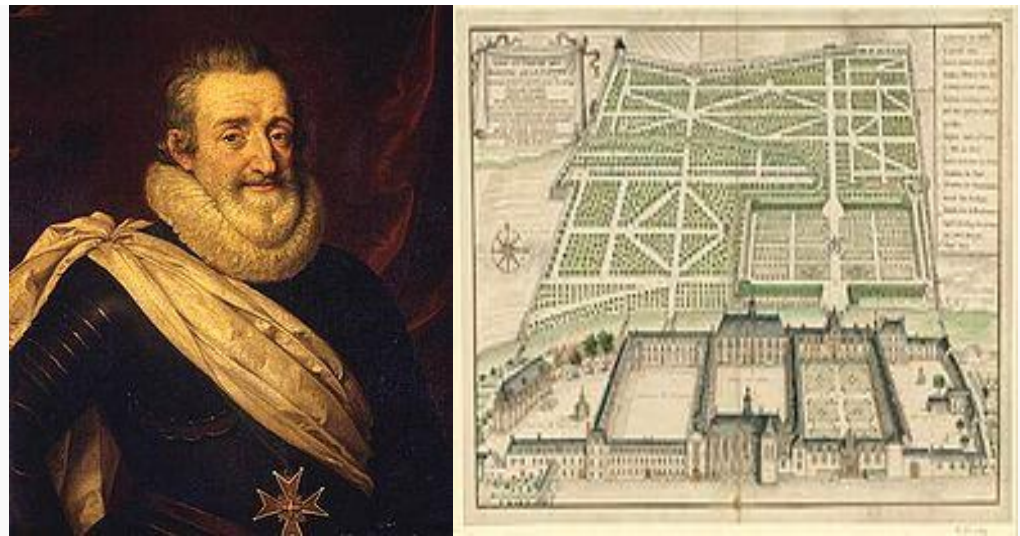

Figura 2. Pintura de Henri IV, fundador do Colégio de La Flèche.

Fonte: fr.wikipedia.org.

O currículo do Colégio La Flèche, embora abordando a Matemática e a Filosofia, exibe um rico e vasto elenco de conteúdos listados abaixo, com destaque para as Regras dos Professores de Filosofia (FARRELL, 1970).

Regras do Provincial (1-40)

Regras comuns a todos os professores das Faculdades Superiores (1-20)

Regras particulares dos professores das Faculdades Superiores

Professor de Escritura (1-20)

Professor de Hebreu (1-5)

Professor de Teologia (1-14)

Professor de Teologia Moral (1-10)

Regras dos Professores de Filosofia

Professor de Filosofia (1-20)

Professor de Filosofia Moral (1-4)

Professor de Matemática (1-3)

Regras do Prefeito de Estudos Inferiores (1-50)

Regras dos estudantes da Companhia (1-11)

Regras das Academias

O Ratio Atque Institutio Studiorum foi o resultado de muitos anos de estudo, planejamento e experimentação, conduzidos por grandes administradores e professores da Universidade de Paris. Fundada em 1170, essa Universidade foi divida em 13 Universidades independentes, refletindo cada uma o rigor acadêmico e as heranças de seu grande passado.

O grande artífice do Colégio La Fléche foi o Padre Jerônimo Nadal (1507 - 1580), colaborador de Santo Inácio de Loyola, ou Íñigo López , fundador da Companhia de Jesus, nascido em 1491 em Azpeitia, País Basco e falecido em 1556 em Roma, Itália. Reestruturado em 1586 e em 1591, o Colégio e a própria Sociedade de Jesus foram por 
vários anos, a partir de 16 de agosto de 1733, silenciados sob responsabilidade do Papa Clemente XIV. Para a educação, em particular, os prejuízos foram enormes, resultando no fechamento de 546 escolas na Europa e 123 em outras partes do mundo. Apenas Frederico II da Prússia e Catarina II da Rússia conseguiram impedir essa medida da Igreja Católica. Felizmente, em 1804, a pedido do Rei Ferdinando e sob autorização do Papa Pio VII, os jesuítas retornaram nas chamadas Duas Sicílias. Alguns anos depois, a 7 de agosto de 1814, ocorreu o seu completo retorno em todo o mundo.

Studiorum.

A Figura 3 mostra o retrato anônimo do Padre Jerônimo Nadal, ao lado do Ratio

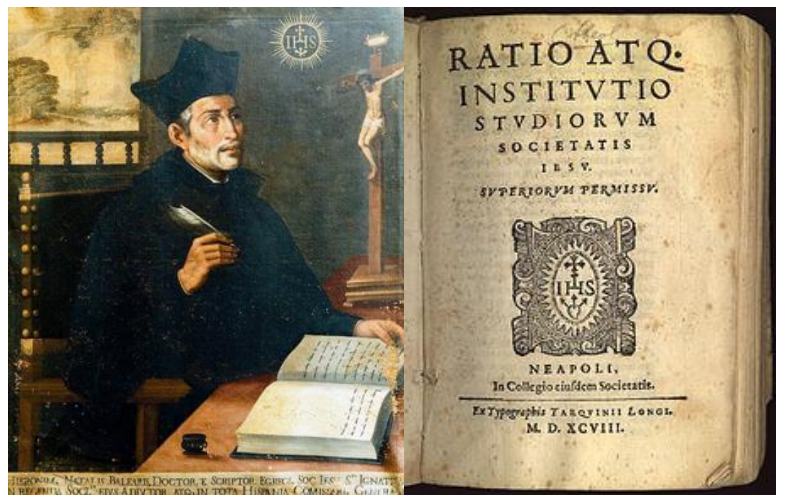

Figura 3. O grande fundador acadêmico do Collège La Flèche. Fonte: Societat Arqueòlogica Lul.liana, de Palma de Mallorca.

Sob uma proposta curricular rigorosa e as exigências e princípios da Companhia de Jesus, destacou o Padre Leonel Franca em França (1952):

"No desenvolvimento da educação moderna o Ratio Studiorum ou Plano de Estudos da Companhia de Jesus desempenha um papel cuja importância não é permitida desconhecer ou menosprezar. Historicamente, foi por esse Código de ensino que se pautaram a organização e a atividade dos numerosos colégios que a Companhia de Jesus fundou e dirigiu durante cerca de dois séculos, em toda a terra. Ordem consagrada ao ensino pela Constituição escrita por seu próprio fundador, a Companhia, onde quer que entrasse a exercer os seus ministérios, instituía logo e multiplicava rapidamente os seus estabelecimentos de ensino. Em 1750, poucos anos antes de sua supressão (1773) por Clemente XIV, a Ordem de Inácio dirigia 578 colégios e 150 seminários, ao todo, 728 casas de ensino.

[...]

Não só a obra educativa dos colégios da Companhia foi um dos fatores mais eficientes da contra-reforma católica, senão também ela se acha ligada a grande parte da aristocracia intelectual dos últimos séculos. $\mathrm{Na}$ 
França, S. Francisco de Sales, Corneille, Moliere, Fontenelle, Descartes, Bossuet, Monstesquieu, Malesherbes, Rousseau, La Condamine, Diderot, Buffon, Langrage, Richelieu, Conde, Cauchy, Flechier, Fleury, Lamartine, Foch; na Espanha, S. João da Cruz, Cervantes, Calderón, Lope de Veja, José Zorrila, Rubem Dario, Ramon Jimenes; na Itália, Tasso, Alfiere, Vico, Goldoni, Segneri, Bartoli, Prospero Lambertini (Bento XIV); na Bélgica, Justo Lipsio; na Irlanda, O'Connel; em Portugal e na América Latina, Antonio Vieira, João de Lucena, Baltazar Teles, Zorrilla de S. Martin, para não lembrar senão estrelas de primeira grandeza, saíram dos Colégios da Companhia (FRANÇA, 1952, p. 1).

Descartes, em particular, concluiu seus estudos em La Flèche por volta de 1614, iniciando, em sequência, os estudos de Direito na Universidade de Poitier, atendendo a vontade de seu pai, ali graduado. Mas não foi nessa área que aprofundou seus estudos e sim em Filosofia, Lógica, Física e, principalmente, em Matemática - ciência pela qual nutria particular interesse.

\section{René Descartes: viagens e estudos}

Antes de sua relação com a Geometria Analítica, Descartes buscou estabelecer uma trajetória científica traçada a partir da Revolução Científica europeia, entre os séculos XVI e XVII. Para bem entender suas relações e obras, concordando com Fonseca (2013), é necessário que se compreenda bem a sua época, contextualizando-o adequadamente em seu tempo.

Suas intenções com a Matemática eram amplas e, a princípio, superavam os seus embasamentos teóricos. Assim, munido de seus primeiros estudos em La Flèche e livre de limites financeiros e familiares, decidiu-se por buscar em outros países, respostas para suas maiores indagações. Pode, assim, conforme O'Connor e Robertson (2014), buscar contatos que ampliaram sobremaneira os seus conhecimentos na área:

De 1620 a 1628 Descartes viajou pela Europa, passando algum tempo na Bohemia (1620), Hungria (1621), Alemanha, Holanda e França (162023). Ele permaneceu um período em Paris, em 1623, quando manteve contato com Marin Mersenne, importante por aproximá-lo do mundo científico depois de muitos anos, e com Claude Bydorge. De Paris viajou para a Itália, passando pela Suiça, permanecendo por um período em Veneza e em Roma, retornando, novamente, para a França (1625) (O’CONNOR; ROBERTSON, 2014, p. 3).

Mas que outros impulsos o moviam na direção dessas viagens? A editora L\&PM, de sua ótima edição sobre o "Discurso do Método", extrai no L\&PM-Blog (2015) as considerações: 
O impulso para a viagem, para a aventura, nasce de uma profunda inquietação com o tipo de ensinamento, com as formas de filosofia e de ciência reinantes naquela época. Para ele, a filosofia e a ciência estavam esclerosadas, pois tinham como ponto de referência indubitável e verdadeiro a filosofia escolástica, de cunho tomista-aristotélico, como se não mais coubesse a pergunta pela verdade de algo, de uma proposição, mas tão-somente uma disputa sobre a interpretação de "verdades" tidas por eternas. Resgastar o princípio mesmo da filosofia implicava um pensamento autônomo, livre de quaisquer amarras, e, sobretudo, livre de toda espécie de preconceito. Se cada um de nós almeja ter uma ideia verdadeira, devemos preliminarmente afastar esse tipo de préconhecimento, de pré-conceito, sedimentado no senso comum, impeditivo de que se possa pensar diferentemente. O senso comum de uma época, qualquer que seja, não é nem pode ser critério de verdade.

Descartes seguiu em 1617 para a Holanda e se alistou no exército de Maurício de Nassau. Mais interessante do que as pouco prováveis batalhas vividas, foram contatos científicos como o descrito por Rouse Ball (2010), à página 269 do Capítulo XV - History of Modern Mathematics from Descartes to Huygens - circ. 1635-1675. De fato, foi estimulado pela tradição e desejo de estender contatos com homens de posição, como o médico holandês Isaac Beeckman, dirigente do College Dutch em Dort, que Descartes aprofundou, durante os anos seguintes, seus estudos em Física e em Matemática. Do contato inusitado com Beeckman, breves estudos e a própria intuição que lhe faltava para formalizar a Geometria Analítica produziram novidades em 1619:

Na noite do dia 10 de novembro de 1619, em uma cidade próxima de Ulm ou Neuberg, quando estava em campanha no Danúbio, Descartes teve a intuição da Geometria Analítica e de um novo método para a organização de uma filosofia após ter aproveitado todo o seu tempo de laser no estudo da Matemática (BALL, 2010, p. 269).

Posteriormente, em 1626, Descartes mudou-se para Paris, interessado inicialmente em aspectos sociais da cidade. Foi em 1637, porém, que reencontrou o Padre Marin Mersenne, frade e matemático do Convento Mínimo da Anunciação, de Paris, cujos objetivos científicos eram bastante progressistas e abertos. Várias de suas obras, a supor pelos títulos, guardam afinidade com os temas trabalhados por Descartes, como, por exemplo:

- La vérité des sciences contre les sceptiques et les pyrrhoniens, 1625 (A verdade das ciências contra os céticos e os indecisos)

- Euclidis elementorum libri, Apollonii Perga conica etc., 1626 (O livro elementar de Euclides, Cônicas de Apolônio de Perga etc)

- Questions theólogiques, physiques, morales et mathématiques, 1634 (Questões teológicas, físicas, morais e matemáticas) 
- Cogitata physico-mathematica, 1644 (Pensamentos físico-matemáticos)

- Universa geometria mixtceque mathematica synopsis, 1644 (Sinopse de toda geometria e de matemáticas diversas)

Do período passado na Holanda, Descartes levou para a França, sem concluir, o trabalho Regulae ad directionem ingenii (Regras para a direção do Espírito), com publicação póstuma em 1701. Entre 1629 e 1633, concluiu os tratados Traité de l'Homme (Tratado do Homem) e Le Monde (ou Traité de la Lumière - Tratado da Luz). Embora a Matemática já estivesse presente em seus primeiros trabalhos, principalmente na análise de fenômenos físicos, isso se intensificou progressivamente nos anos seguintes, não mesmo tendo postergado algumas publicações, assustado com a condenação de Galileu Galilei (1564 - 1642). Tudo isso fez com que sua fama crescesse e se projetasse bastante pela Europa, ampliada por contatos mantidos com Claude Clerselier, confidente, discípulo e editor de algumas de suas obras.

\section{O Discurso do Método}

Descartes, em sua obra máxima Discours de la méthode pour bien conduire la raizon et chercher la vérité dans les sciences (Discurso do método para bem conduzir a razão e procurar a verdade nas ciências), incluiu, conforme Descartes (2001), três apêndices, $L a$ Dioptrique (A Dióptrica), Les Mètéores (Os Meteoros) e Géométrie (Geometria). Esta obra foi publicada em Leyden em 1637, inspirada e motivada pela universalidade da razão, a intuição e a dedução. A Figura 4 apresenta o retrato de René Descartes ao lado do Frontispício da $1^{\text {a }}$ edição do Discurso do Método e de sua casa natal.

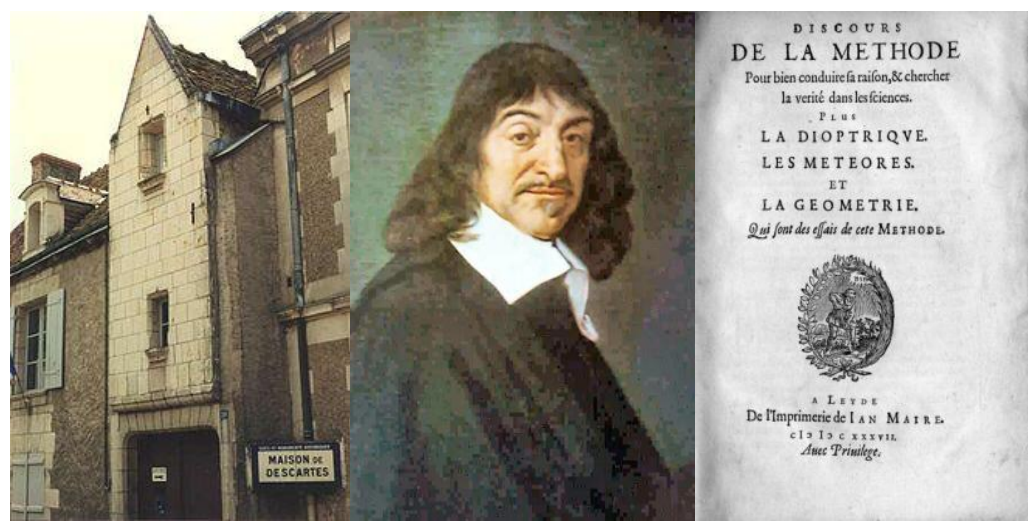

Figura 4. René Descartes, por Frans Hals. Fonte: fr.wikipedia.org

Dividido em seis partes, o Discurso do Método busca, nas certezas da Matemática, a verdade de cada uma:

- Considerações sobre a ciência 
- As principais regras para a prática científica

- Algumas das justificativas do método

- As provas da existência de Deus e da alma humana e fundamentos da metafísica

- Aplicações do método à física e à medicina e particularidades da alma humana

- Razões e crenças de Descartes sobre o que é essencial para o progresso do conhecimento

Embora se pretenda destacar aqui a Geometria, não se deve ignorar que o seu surgimento sofreu influência da Filosofia de natureza escolástica, que era fundamental para os propósitos curriculares medievais do Colégio de La Flèche. Ali, sob a Filosofia e a Lógica de Aristóteles, os jesuítas buscavam unir a razão e a fé aos demais princípios e desejos da Igreja Católica, como a Providência, a Revelação Divina e a Criação. A célebre frase "Penso, logo existo" encontra-se na quarta parte da obra, e ajusta-se claramente ao entendimento e ao prazer de Descartes pela Matemática, como ferramenta sólida para sua filosofia:

Comprazia-me sobretudo com as Matemáticas, por causa da certeza e da evidência de suas razões; mas não notava ainda seu verdadeiro emprego, $e$, pensando que serviam apenas às artes mecânicas, espantava-me de que, sendo seus fundamentos tão firmes e tão sólidos, não se tivesse edificado sobre elas nada de mais elevado (DM, I, p. 32).

Observa-se que o uso de sua genialidade vai bem além do uso de uma notação simples e clara para a Álgebra, como $(\mathrm{a}, \mathrm{b}, \mathrm{c}, \ldots)$ para as quantidades e $(\ldots, \mathrm{x}, \mathrm{y}, \mathrm{z})$ para as incógnitas. Genialidade que abriu espaço para a expansão da física quantitativa e para o surgimento de novas teorias matemáticas. $\mathrm{O}$ que se sabe é que, mesmo optando por um trabalho científico solo, sem jamais ter sido um acadêmico, tornou-se respeitado por suas posições e produções científicas. Mas que posições defendia e de onde vinha sua credibilidade? Para Fonseca (2013), herdara do passado, principalmente do passado grego, e defendia como correção e transformação para o futuro, para avanço da Matemática:

Se toda a filosofia posterior se torna inteligivel porque se situa e se posiciona relativamente a Descartes, a filosofia cartesiana, ela própria, com as profundas novidades que traz, arrisca-se a ser olhada apenas como mais um estranho modo de ver a realidade se não for perspetivada a partir das também profundas mudanças que ocorrem e que caracterizam a sua época. De facto, como perceber o que é e em que consiste a chamada "revolução cartesiana" e qual o seu alcance? E como perceber verdadeiramente o significado da expressão "primeiro filósofo moderno" aplicada a Descartes? Se assim é, então que época é esta? Que é que a caracteriza como época distinta das anteriores? Quais são as grandes modificações que ocorrem e quais são as profundas novidades que essas transformações acarretam e implicam? (FONSECA, 2013, p. 65). 
Ainda à página 65, sua autora destaca Galileu e Descartes como grandes destruidores dos antigos dogmas e, ao mesmo tempo, os grandes reconstrutores do novo conhecimento e de uma nova imagem do mundo. E destaca a Geometria Analítica como uma teoria insubstituível da Matemática, tanto em seu formalismo quanto em suas aplicações.

\section{A Geometria Analítica - sua presença no Discurso do Método}

Foi sob o racionalismo de Descartes e sua crença nas potencialidades dessa nova ciência que a Geometria Analítica surgiu como um dos três apêndices do Discurso do Método, em um contexto que começava a aproximar a Álgebra e a Geometria clássica. Algo bastante perceptível, por exemplo, na solução cartesiana da quadratura do círculo, conforme Crippa (2010):

Durante a primeira metade do século XVII, o problema de saber se a quadratura do círculo é possível - isto é, se é possível construir, com métodos geométricos, um quadrado com área igual à de um círculo dado - permaneceu um problema aberto na agenda dos matemáticos (MANCOSU, 1996, p. 79 apud CRIPPA, 2010).

Mas, quanto às questões de geometria que eles vos prometem me propor, as quais não conseguem solucionar e crêem não poder ser resolvidas pelo meu método, eu penso que me encontro em uma posição desvantajosa. Com efeito, primeiramente, é contra o estilo dos geômetras propor aos outros questões que eles mesmos não podem resolver. Depois, há as que são impossíveis, como a quadratura do círculo etc., há outras que, embora sejam possíveis, estendem-se, contudo, para além dos limites que coloquei, não porque exigem outras regras ou mais espírito, mas porque é preciso mais trabalho (...). Enfim, há as que pertencem à aritmética e não à geometria, como aquelas de Diofanto (AT, 2, 90-1 apud CRIPPA, 2010).

[...]

Então, descreverei a curva quadratriz geometricamente dessa maneira. Seja o arco BD dividido em várias partes iguais, e um dos dois outros lados $A D, B C$ no mesmo número de partes iguais. Essa divisão será muito simples, se for primeiramente bissectado seja o arco DB seja um dos dois lados $A D, B C$ e, em seguida, cada parte for novamente bissectada, e assim posteriormente tanto quanto se quiser (CLAVIUS, 1604, p. 321 apud CRIPPA, 2010).

As intersecções dos segmentos traçados desse modo formarão um conjunto de pontos pertencentes a uma quadratriz. No fragmento citado, Clavio declara oferecer uma construção da quadratriz mais precisa e mais geométrica que a apresentada na Collectio de Pappus. Ele se refere, em particular, a uma das duas objeções relatadas pelo próprio Pappus e 
atribuídas a Sporus. Segundo este último, o ponto de intersecção entre a quadratriz e o eixo não pode ser construído, pois os dois segmentos em movimento coincidirão sobre o eixo horizontal, e o traçado da curva cessará antes de encontrá-lo (CLAVIUS, 2010, p. 610 apud CRIPPA, 2010).

A Figura 5 mostra a representação da curva quadratriz de Pappus por Descartes. A demonstração completa desse teorema pode ser encontrada em Crippa (2010). Descartes inicia, aí, o processo de reformulação da Geometria, mantendo a base axiomática de Euclides, mas incorporando a Álgebra à sua linguagem. Conforme a Stanford University The Stanford Encyclopedia of Philosophy (2014):

O primeiro livro se inicia com uma explicação dos princípios da Geometria Analítica, e contém um discurso sobre um problema clássico de Pappus (do qual tratamos anteriormente).

[...]

No segundo livro, Descartes aborda, em destaque, problemas sobre curvas geométricas.

[...]

O terceiro livro contém uma análise, sob nova linguagem, da Álgebra da época.

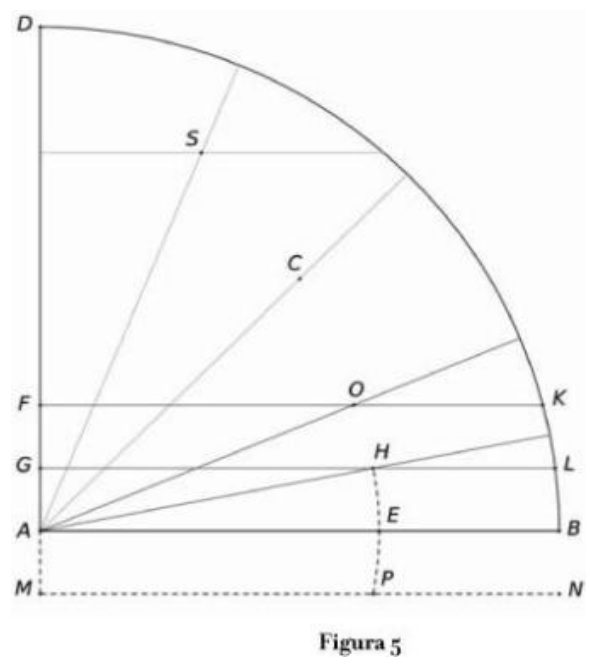

Figura 5. Quadratura do círculo.

Fonte: Crippa (2010)

Observa-se, aqui, que Fermat é coautor da Geometria, mas parte de outros problemas e utiliza outra linguagem. Essa comparação não faz parte do presente trabalho. 


\section{A inspiração de Descartes}

Inspirado no Teorema de Pappus, que resolveu a pedido do matemático holandês Golius, Descartes, em 1637, começou a desenvolver os princípios e a linguagem da Geometria Analítica no Livro I, relacionando, em particular, operações aritméticas com operações geométricas. Cabe lembrar aqui, sem maiores considerações a respeito, que o Livro II subdivide-se em quatro partes, da classificação de curvas até aplicações em Dióptrica, e que o Livro III apresenta uma análise ampla sobre equações polinomiais.

Problemas de Pappus, na Figura 6, dão mostras das inovações algébricas e geométricas de Descartes.
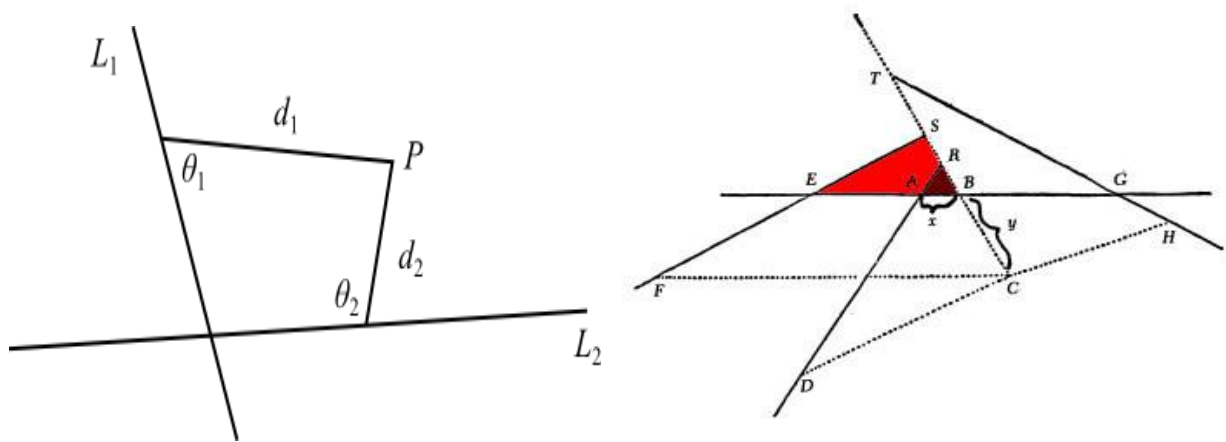

Figura 6. Um problema restrito e um problema geral de Pappus

Fontes: Stanford Encyclopedia of Philosophy; http://nonagon.org/ExLibris/descartes-lageometrie.

O problema à esquerda trata de duas retas $\left(\mathrm{L}_{1}, \mathrm{~L}_{2}\right)$, dois ângulos $\left(\theta_{1}, \theta_{2}\right)$, e uma proporção $\beta$, em que $\mathrm{d}_{1}$ aparece como a distância entre uma reta oblíqua $\mathrm{L}_{1}$ e $\mathrm{P}$, sendo que $\mathrm{P}$ cria o ângulo $\theta_{1}$ com $\mathrm{L}_{1}$. Por outro lado, $\mathrm{d}_{2}$ é a distância entre o ponto $\mathrm{P}$ no plano e a reta oblíqua $\mathrm{L}_{2}$, sendo que $\mathrm{P}$ cria o ângulo $\theta_{2} \operatorname{com~} \mathrm{L}_{2}$. O problema é encontrar todos os pontos $\mathrm{P}$ tais que $d_{1}: d_{2}=\beta$, pontos que ocorrem, como pode ser visto, à direita de $L_{1}$ e à esquerda de $\mathrm{L}_{2}$. O segundo exibe características das seções cônicas tratadas por facsimile pela Smith/Latham em 1925, conforme Ex Libris (2015), a partir de caracterização de Descartes de 1637, excetuando-se a cor e a notação para $\mathrm{x}=\mathrm{AB}$ e $\mathrm{y}=\mathrm{BC}$. Sugere-se, sobre a resolução de problemas como o que exige a Figura 6 à direita, a referência Grabiner (1995), às páginas 86 e 87.

Tanto quanto construir uma nova Geometria, Descartes, como assinala Neovius (2013), estabelece uma nova estrutura e nova linguagem matemática, abrindo espaço para reconhecer e classificar geometricamente curvas, a começar pelas curvas clássicas da antiguidade grega, tratadas com régua e compasso. Classifica, depois, as curvas geométricas, atualmente denominadas curvas algébricas, construtíveis pela interseção de outras curvas ou por certos movimentos contínuos que cumpram exatidão geométrica adequada e conclui, classificando as curvas mecânicas como aquelas que não podiam ser 
construídas como as demais. Além dos matemáticos dos períodos de 300 a.C. e 300 d.C., Descartes destaca entre os matemáticos do século XVII, o jesuíta Cristóvão Clávio e inova, por fim, com suas classes de curvas geométricas, baseadas em suas equações algébricas.

Pode-se verificar ainda em Neovius (2013), que Pierre de Fermat (1601 - 1665), Gilles de Roberval (1602 - 1675) e Florimond de Beaune (1601 - 1652), após 1637 apresentam sumários e métodos cartesianos justificando a importância e as potencialidades da Geometria Analítica, principalmente favorecida por sua terminologia, uso das coordenadas polares e generalização do método voltado para formas tridimensionais. François Viète (1540 - 1603) complementa os matemáticos desse período, destacando-se em 1591 tanto pelas inovações da linguagem matemática quanto da álgebra simbólica, através da obra Isagoge in artem analyticum (Introdução à arte analítica).

A Figura 7 destaca as capas das obras de Pappus $(290$ - 350) e de Diofanto (200 284) entre localização de outros matemáticos do mundo greco-romano.

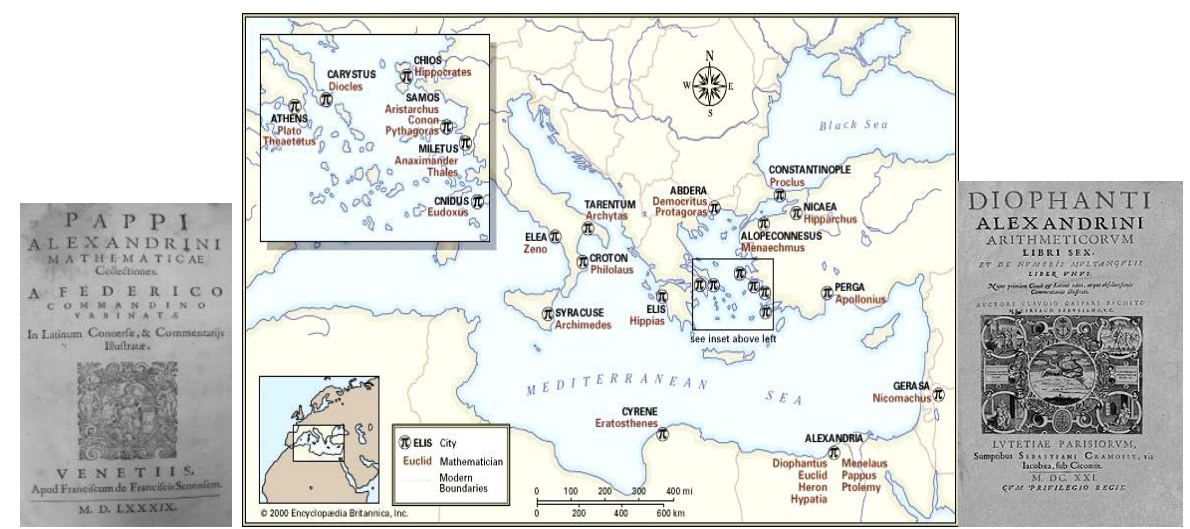

Figura 7. Capas das obras de Pappus e de Diofanto. Ao centro, localização de outros matemáticos do mundo greco-romano.

Fontes: Enciclopédia Britânica; Inc. www.unit.eu.

\section{Complementos: a presença de Descartes na educação contemporânea}

Pretende-se aprofundar o presente estudo em novos trabalhos, que destaquem aspectos pouco conhecidos ou inexplorados da educação e da matemática dos jesuítas, além dos currículos que introduziram em novas escolas pelo mundo. Além das obras anteriormente citadas e de outras mais recentes, Bertato (2011), Bloch (2001), Cardoso (1997), D’Ambrósio (2012), Forbes (1977), Freire (2009), Hawking (2005), Hobsbawm (1997), Villalta (2002), Struik (1948), Jésuits de La Province de France (2015) e Larousse (2015) permitem ampliar a percepção necessária para tais objetivos. Relativamente ao trabalho em conclusão, cabem algumas considerações finais. Conforme Serfati (2005), após 1649, com tradução do latim por van Schooten, a Geometria eferveceu entre matemáticos europeus. Descartes ganhou reconhecimento e notoriedade e a Matemática, em contrapartida, entrou em nova era, abrindo espaço para físicos e matemáticos de primeira grandeza, como 
Leibniz e Newton. Sabe-se, de fato, que em poucas décadas, desde sua criação, a Geometria Analítica revolucionou o conhecimento matemático e suas aplicações à Física e foi decisiva na formalização do Cálculo Infinitesimal de Newton e de Leibniz. Novas teorias matemáticas surgiram nos séculos seguintes, e o Cálculo é reformulado com base na Teoria de Limites. Gozou do respeito, da admiração e até de certo grau de inveja de outros cientistas da época, como Gottfried Leibniz (1646 - 1716), mas sofreu, após a morte, a proibição de ter suas obras filosóficas divulgadas na França de Luis XIV. Sua Matemática se manteve viva, de toda forma, juntamente com novas teorias que iam surgindo. Hoje seu nome segue alimentando o interesse e gerando estudos e obras histórico-filosóficas de autores como Stephen Hauking e Roger Penrose.

E quanto à sua presença na Educação Matemática em todo o mundo e no Brasil, em particular?

Em termos globais, mesmo não tendo Descartes vivido a realidade de uma academia ou exercido a docência em qualquer nível, estabeleceu resultados e princípios que o integraram à Educação em todos os níveis e áreas de formação. Particularmente no que se refere à Matemática, o nome e a Geometria Analítica de Descartes transitam do Ensino Básico a todos os demais níveis de ensino e áreas de Pesquisa e Aplicação, como exemplificam, transitando entre a Filosofia e a Matemática (KHANACADEMY, 2015a; KHANACADEMY, 2015b).

Mondini (2013) destaca que no auge da fase colonial e antes da expulsão dos jesuítas em 1759 o Sistema Educacional do Brasil era possivelmente orientado pelo Ratio Studiorum. O estudo da Geometria de Euclides se mantinha em destaque e apoiava os estudos iniciais da Física, sendo orientado pelas normas sancionadas por D Pedro I em 15 de outubro de 1827. Assim foram introduzidas nas grandes cidades brasileiras suas Escolas de Primeiras Letras.

D. Pedro I, por Graça de Deus e unânime aclamação dos povos, Imperador Constitucional e Defensor Perpétuo do Brasil: Fazemos saber a todos os nossos súditos que a Assembléia Geral decretou e nós queremos a lei seguinte:

Art. $1^{\circ}$ Em todas as cidades, vilas e lugares mais populosos, haverão as escolas de primeiras letras que forem necessárias.

[...]

Art. $6^{\circ}$ Os professores ensinarão a ler, escrever, as quatro operações de aritmética, prática de quebrados, decimais e proporções, as noções mais gerais de geometria prática, a gramática de língua nacional, e os princípios de moral cristã e da doutrina da religião católica e apostólica romana, proporcionados à compreensão dos meninos; preferindo para as leituras a Constituição do Império e a História do Brasil.

[...]

Carta de Lei, pela qual Vossa Majestade Imperial manda executar o decreto da Assembléia Geral Legislativa, que houve por bem sancionar, sobre a criação de escolas de primeiras letras em todas as cidades, vilas 
e lugares mais populosos do Império, na forma acima declarada (MONDINI, 2013, p. 1).

Surgem, depois, as Escolas Primária e Secundária, voltadas, respectivamente, para crianças de 7 a 13 anos e crianças de 13 a 15 anos. A Constituição Federal de 1937 e depois a de 1988, corrigem muitas de suas falhas, estabelecendo, enfim, que a educação é um direito de todos, além de responsabilidade e obrigação do Estado e da família. O sistema ideal não foi atingido, principalmente em razão das disparidades sociais do país, mas segue motivando os educadores e gestores brasileiros, inspirados, principalmente, na vida e obra do pedagogo e filósofo Paulo Freire (1921 - 1997), e do matemático, educador e pesquisador paulistano Ubiratan D’Ambrósio. Se Descartes assim se referiu um dia ao Colégio Jesuíta Royal Henry-Le-Grand, a sua escola de La Flèche:

Estive numa das mais famosas escolas da Europa. [...] Aqui foi onde plantei as sementes dos meus feitos mais tardios $e$ ao qual estou extremamente agradecido, e o que cada estudante do país necessita e deseja, é ter motivo para se orgulhar de sua escola. Única forma para se plantar as sementes de um futuro verdadeiramente digno, justo e feliz (WIKIPÉDIA, 2015).

conforme Thomson (1972), as sementes de seus feitos teriam crescido sobretudo pelo método, disciplina mental e psicologia do pensamento e da vontade de seus mestres jesuítas.

A Figura 8 exibe a estátua de René Descartes construída pelo Conde Alfred Émile O’Hara em 1846 para a cidade de Haia, na Holanda e com cópia desde 1852 instalada na Praça Anatole France, em Paris. 


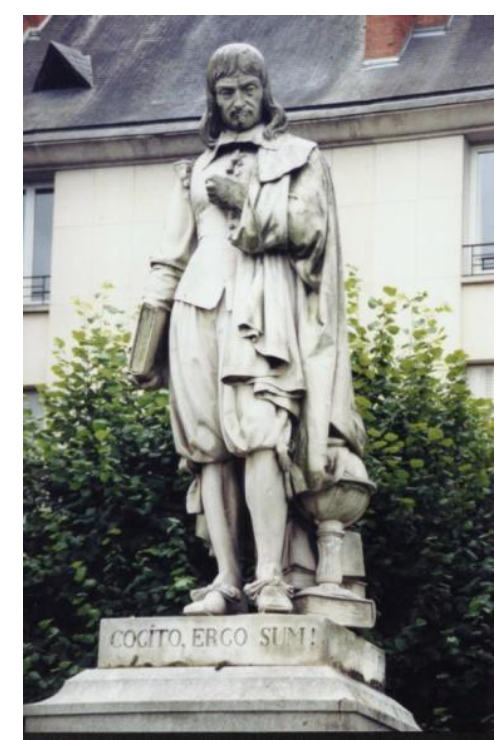

Figura 8. Estátua de René Descartes.

Cogito ergo sum - "Je pense donc je suis".

Fonte: https://upload.wikimedia.org/.

\section{Bibliografia}

BAILLET, A. La vie de monsieur Descartes. Édition des Malassis/Éditions des Équateurs Relié. Pagination, 2012.

BERTATO, F. M. Contribuições dos Pensamentos Medieval e Renascentista para o Desenvolvimento da Matemática. CLE - Unicamp - Brasil, edição especial da Revista Brasileira de História da Matemática. RBHM, v. 11, n. 23, p. 27-38, 2011.

BLOCH, M. Apologia da História ou Oficio de Historiador. Rio de Janeiro: Jorge Zahar Editor, 2001.

CARDOSO, C. F.; VAINFAS, R. Domínios da História: ensaios de teoria e metodologia. Rio de Janeiro: Campus, 1997. Disponível em: <http://www.educ.fc.ul.pt/docentes/opombo/seminario/fermat/geometria_analitica.htm. Acesso em: 01 jun. 2015.

CRIPPA, D. A solução cartesiana da quadratura do círculo. Scientia Zudia, São Paulo, v. 8, n. 4, p. 597-621, 2010.

D’AMBRÓSIO, U. Educação Matematica da Teoria à Prática. Campinas: Papirus, $23^{\mathrm{a}}$ edição, 2012.

DESCARTES, R. Discourse on Method, Optics, Geometry, and Meteorology. Tradução de Paul J. Olscamp. Indianapolis: revised edition Hackett, 2001.

EX LIBRIS. Descartes and La Géométrie. Disponível em: <http://nonagon.org/ExLibris/descartes-la-geometrie>. Acesso em: 01 jul. 2015.

FARRELL, A. P. Conference of Major Superiors of Jesuits 1717: The Jesuit Ratio Studiorum of 1599. N.W. Washington, D. C. 20036, 1970. 
FONSECA, M. J. Sobrevoando a Filosofia de Descartes: o seu Itinerário Filosófico, Millenium, 45, n. 2, p. 63-101, 2013,

FORBES, E. G. Descartes and the Birth of Analytic Geometry. Historia Mathematica, v. 4, n. 2, p.141-151, 1977.

FRANÇA, L. E. S. Introdução de Obras Completas do Pe. Leonel Franca S. J - O Método Pedagógico dos Jesuítas - O "Ratio Studiorum" Introdução e Tradução. Rio de Janeiro: Livraria AGIR Editora, 1952.

FREIRE, P. Pedagogia da autonomia: saberes necessários à prática educativa. São Paulo: Paz e Terra, 2009.

GRABINE, J. V. Descartes and Problem-Solving. Mathematical Magazine, v. 68, n. 2, p. 83-97, 1995.

JÉSUITS DE LA PROVINCE DE FRANCE. La mission de la Compagnie de Jésus aujourd'hui. Disponível em: <http://www.jesuites.com/que-faisons-nous>. Acesso em 02 de jul. de 2015.

HAWKING, S. W. René Descartes. God created the integers: the mathematical breakthroughs that changed history. Running Press, 2005.

HOBSBAWM, E. Sobre História. São Paulo: Companhia das Letras, 1997.

KHANACADEMY. Early Modern: Descartes' Cogito Argument. Disponível em: <https://www.khanacademy.org/partner-content/wi-phi/the-history-of-

philosophy/v/philosophy-descartes-cogito-argument>. Acesso em: 10 jun. $2015 \mathrm{a}$.

KHANACADEMY. Kan Academy Brasil. Disponível em: <https://pt.khanacademy.org/>. Acesso em: 10 jun. 2015 b.

LAROUSSE. René Descartes. Disponível em: <http://www.larousse.fr/encyclopedie/personnage/Descartes/116208>. Acesso em: 02 jul. de 2015.

L\&PM-Blog. René Descartes. Disponível em: <www.lpm.com.br/site/default.asp?TroncoID=805134\&SecaoID=948848\&SubsecaoID=0 $\&$ Template=../livros/layout_autor.asp\&AutorID=062525>. Acesso em: 12 jun. 2015.

MONDINI, F. A Matemática Presente nas Escolas Jesuítas Brasileiras (1549 - 1759). Acta Scientiae, Canoas, v.15, n.3, p. 524-534, 2013.

NEOVIUS, S. René Descartes' Foundations of Analytic Geometry and Classification of Curves. Examensarbete i matematik, 15 hp Handledare och examinator: Gunnar Berg Juni 2013 U.U.D.M. Project Report, 2013.

O'CONNOR, J. J.; ROBERTSON, E. F. René Descartes, 2014. Disponível em: <http://www-history.mcs.st-and.ac.uk/Biographies/Descartes.html>. Acesso em: 12 jun. 2015.

PRADO, M. L. C.; VIDAL, D. G. A Educação na Colônia e os Jesuítas: discutindo alguns mitos. In: VILLALTA, L. C. - (Org.) À Margem dos 500 Anos: reflexões irreverentes. São Paulo: Edusp, 2002, p. 171-184.

BALL, W. W. R. Short Account of the History of Mathematics (1908). Project Gutenberg EBook Mathematics - [EBook \#31246], 2010.

SERFATI, M. René Descartes: Géomètrie. Latin edition 1649, French edition (1637), In: I. GRATTAN-GUINNESS (éd); Landmark Writings in Western Mathematics 1640-1940, Elsevier, 2005, p.1-22. 
STANFORD UNIVERSITY. Stanford Encyclopedia of Philosophy, 2014.

Disponível em: <http://plato.stanford.edu/ http://pt.wikipedia.org/wiki/Folium_de_Descartes>. Acesso em: 12 jun. 2015.

STRUIK, D. J. A Concise History of Mathematics, vol. I, New York Dover Publications, Inc, 1948. Disponível em: <https://archive.org/details/concisehistoryof01stru>. Acesso em: 02 jul. de 2015.

THOMSON, A. Ignace de Loyola et Descartes. Archives de Philosophie, University of Western Ontario, v. 35, n. 1, p. 61-85, 1972.

VILlALTA, L. C. A Educação na Colônia e os Jesuítas: discutindo alguns mitos. In: PRADO, M. L. C.; VIDAL, D. G. (Org.), À Margem dos 500 Anos: reflexões irreverentes. São Paulo: Edusp, 2002, p. 171-184.

WIKIPÉDIA La Flèche. Disponível em: <https://pt.wikipedia.org/wiki/La_Fl\%C3\%A8che>. Acesso em: 02 jul. de 2015.

\section{Tadeu Fernandes de Carvalho}

Faculdade de Matemática PUC - Campinas - Brasil

e-mail: tadeu_fc@puc-campinas.edu.br

Priscila de Moraes

Faculdade de Matemática PUC - Campinas - Brasil

e-mail: primoraessampra@hotmail.com

Denise Helena Lombardo Ferreira

Faculdade de Matemática PUC - Campinas - Brasil

e-mail: lombardo@ puc-campinas.edu.br 